\title{
Evaluation of Terminalia chebula Extract for Anti-Arthritic Efficacy and Safety in Osteoarthritic Dogs
}

Nichole Murdock ${ }^{1}$, Ramesh Gupta $\mathbf{C}^{1^{*}}$, Natalia Vega ${ }^{1}$, Katie Kotora ${ }^{1}$, Jean Miller ${ }^{1}$, John Goad $\mathbf{T}^{1}$, Michelle Lasher $\mathbf{A}^{1}$, Terry Canerdy $\mathbf{D}^{1}$ and Sanyasi $\mathbf{R}$ Kalidindi ${ }^{2}$

${ }^{1}$ Murray State University, Murray/Hopkinsville, KY, USA

${ }^{2}$ Natreon Inc, New Brunswick, NJ, USA

"Corresponding author: Ramesh Gupta C, Murray State University, Murray/Hopkinsville, Breathitt Veterinary Center, Toxicology Department, P.O. Box 2000; 715 North Drive, Hopkinsville, KY 42240-2000, USA, Tel: (270) 886-3959; Tel: (270) 886-4295; E-mail: rgupta@murraystate.edu

Rec date: Dec 17, 2015; Acc date: Jan 18, 2016; Pub date: Jan 20, 2016

Copyright: $\odot 2016$ Murdock N, et al. This is an open-access article distributed under the terms of the Creative Commons Attribution License, which permits unrestricted use, distribution, and reproduction in any medium, provided the original author and source are credited.

\begin{abstract}
The present investigation was undertaken to assess anti-inflammatory and anti-arthritic efficacy and safety of $T$. chebula extract (TCE) in moderately osteoarthritic (OA) dogs. Dogs with OA received either $500 \mathrm{mg}$ placebo or 500 $\mathrm{mg}$ TCE twice daily for 150 days. On a monthly basis, dogs were given a full physical exam and were evaluated for arthritic pain (overall pain, pain upon limb manipulation, and pain after physical exertion), inflammation (erythrocyte sedimentation rate, ESR), and analysis of complete blood count (CBC) and serum biomarkers of liver (bilirubin, ALT, and AST), kidney (BUN and creatinine), and heart and skeletal muscle (CK) functions. Elbow and stifle joints were radiographed on day 0 and day 150 for evaluation of arthritic progression. Dogs given TCE showed significant $(P<0.01)$ reductions in overall pain, pain upon limb manipulation, and pain after physical exertion by day 90 , with maximum effects on day $150(81.2 \%, 81.5 \%$, and $84.2 \%$, respectively). A marked reduction in ESR coincided with pain reduction in TCE-treated dogs, which was indicative of anti-inflammatory effect of TCE. Radiographic evidence also indicated slowed progression of OA in joints examined. No significant change occurred in physical parameters, CBC parameters, or serum biomarkers in dogs on placebo or treatment, which suggested that TCE was well tolerated. It can be concluded that TCE, by having many active principles (chebulagic acid, chebulinic acid, corilagin, hydrolysable tannoids, etc.) might have provided antioxidant, anti-inflammatory and anti-arthritic effects in dogs without causing any side effects.
\end{abstract}

Keywords: Terminalia chebula extract; Nutraceutical; Canine Osteoarthritis; Antioxidant; Anti-inflammatory; Anti-arthritic; Dietary supplement

\section{Introduction}

Osteoarthritis (OA) is a debilitating, degenerative, and painful inflammatory disease that affects the synovial joints, and is highly prevalent in dogs [1,2]. Currently, more than $20 \%$ of the adult and $80 \%$ of the geriatric dog population in the US ( $>80$ million) suffer from OA [3]. A number of factors (injury/trauma, aging, excessive or lack of exercise, genetic predisposition, poor nutrition, obesity, and environmental factors) can contribute to OA in dogs [4-8]. Often, large breed dogs (German Shepherds, Labrador Retrievers, Siberian Huskies, Rottweilers, and others) are prone to develop OA $(>45 \%)$ as compared to smaller breeds $[9,10]$. Common clinical signs of OA include limping, immobility, stiffness of joints, crepitus, periarticular swelling, and pain upon manipulation of the joint and lameness [3,11-17].

Pathophysiology of OA is complex and it needs a brief discussion before selection of disease modifying anti-osteoarthritic agents [12,18-21]. OA is a chronic inflammatory joint disease that slowly progresses and causes degeneration of the cartilage, hypertrophy of bone at the margins, and changes in the synovial membrane that eventually results in pain and stiffness of joints. Cells in damaged joints release cytokines (IL- $1 \beta$ and IL-6), tumor necrosis factor- $\alpha$ (TNF- $\alpha$ ), followed by stimulation of mitogen activated protein kinase (MAPK), matrix metalloproteinases (MMP-1, MMP-3, and MMP-13), inducible nitric oxide synthase (iNOS), cyclooxygenase-2 (COX-2), phospholipase 2A, nitric oxide (NO), prostaglandin E2 (PGE2), and platelet activating factor (PAF). These cascading events and many others cause inflammation, subchondral bone thickening, breakdown of proteoglycans and destruction of cartilage [19,22-29].

In a clinical setting, veterinarians make a diagnosis of $\mathrm{OA}$ in dogs based upon physical examination and radiographic evidence $[2,13,16,20,29,30]$. CT scan and/or MRI findings reveal changes of the joint and cartilage degeneration, which are consistent with OA, but are limited to humans and experimental studies [31-33].

Currently, the management of $\mathrm{OA}$ in dogs is usually aimed at minimizing joint pain by reducing inflammation, slowing the progression of cartilage degeneration and improving cartilage repair, thereby increasing the joint's flexibility and quality of life of the animal $[17,20,29,34,35]$. Currently, veterinarians have many options for managing the signs and symptoms of $\mathrm{OA}$, including pharmaceuticals, nutraceuticals, nutrition, surgery, gene therapy, stem cell therapy, laser therapy, physical therapy, and acupuncture [9,15,29,34,36-41]. To alleviate OA associated inflammation and pain, veterinarians often use nonsteroidal anti-inflammatory drugs (NSAIDs), such as carprofen (Rimadyl), meloxicam (Metacam), firocoxib (Previcox), etc., [42,43]. Most NSAIDs inhibit the activity of the COX enzymes (COX-1 and COX-2) that produce prostaglandins [44], which are important factors for the pathogenesis of inflammation, swelling, pain and fever $[42,45,46]$. NSAIDs eliminate pain, but do not eliminate signs and symptoms of active disease, nor do they repair cartilage. Furthermore, the use of NSAIDs can be linked to side effects, such as hepatic and 
renal dysfunction [47-49] reduced appetite, vomiting, and gastrointestinal upset and bleeding [50-54]. Additionally, NSAIDs have been reported to inhibit bone healing [55]. Recently, Lees et al. [56] indicated that mavacoxib (Trocoxil, a selective COX-2 inhibitor) can be an alternative to NSAIDs that indiscriminately inhibit both COX-1 and COX-2. Of course, the use of mavacoxib also has limitations with regard to dog weight (contraindicated in dogs weighing $<5 \mathrm{~kg}$ ) and duration of treatment (not for $>6.5$ months).

Under these circumstances, the long-term use of safe modalities is warranted. Presently, veterinarians commonly choose nutraceuticals to manage the signs and symptoms of OA in dogs $[57,58]$. In the past two decades, among all nutraceuticals, glucosamine and chondroitin sulfate have been predominantly used in the treatment of canine OA [13,58-61]. In clinical trials, nutraceuticals such as glucosamine and chondroitin sulfate and/or undenatured type II collagen [13,60-62] Crominex $^{\odot}-3+$ [16] purified shilajit [30], avocado/soybean unsaponifiables [63], green lipped mussel [35,64] and curcumin [65] have been found significantly effective in ameliorating OA pain and have shown to be safe for long-term use in canines.

Terminalia chebula Retzius (T. chebula Retz. Combretaceae), commonly known as Black Myrobalan or Harad (mentioned as 'King of medicines" in Ayurvedic Materia Medica), is known to contain several bioactive constituents that exert a variety of pharmacological actions [66]. The present investigation was undertaken to evaluate the anti-inflammatory and anti-arthritic effects of TCE and its safety in moderately osteoarthritic dogs.

\section{Material and Methods}

\section{Experimental design}

Animal selection (inclusion/exclusion) criteria: Ten client-owned arthritic dogs (each weighting between 40-60 pounds) were selected for the present investigation based on the signs of arthritis (joint stiffness, lameness, and pain at the level of moderate severity) and radiographic evidence. Any arthritic dog having any other serious disease or complications related to hepatic, renal, or cardiovascular systems, or tumor/cancer, was not included in the study. Any dog infested with intestinal parasites (Giardia or Cryptosporidium) was also excluded. Throughout the study, dogs remained with their owners. Before initiation of any experiments, IACUC approval and owners consents were obtained.

Animal treatment: Standardized $T$. chebula aqueous extract (AyuFlex) $500 \mathrm{mg}$ capsules and Placebo capsules were supplied by Natreon, Inc., New Brunswick, NJ, USA. In Group-I, five dogs received placebo (500 mg twice daily); and in Group-II, five dogs received $T$. Chebula extract (500 mg twice daily; one capsule $1 \mathrm{~h}$ before morning meal, and one capsule $1 \mathrm{~h}$ before evening meal) for a period of 150 days. None of the dogs received any other treatment for a period of 3 to 4 weeks before or during the study period. The study was conducted double-blinded, that is the investigators or dog owners had no knowledge of the content(s) of white colored capsules.

Physical examination: On a monthly basis, dogs were evaluated for physical parameters, including body weight $(\mathrm{kg})$ using a digital scale, heart rate (beats/min) using a stethoscope, and rectal temperature $\left({ }^{\circ} \mathrm{F}\right)$ using a thermometer. Respiration rate was auscultated and recorded using a stethoscope; however, some dogs could not be evaluated due to excessive panting, and therefore data could not be statistically analyzed and are not included in this paper.

Pain measurement criteria: On a monthly basis, each dog was evaluated for arthritis associated pain (overall pain, pain upon limb manipulation, and pain after physical exertion) for a period of five months, using a Glasgow scoring system. In brief, overall pain, on a scale of $0-10$, was graded as: 0 , no pain; 2.5 , mild pain; 5 , moderate pain; 7.5, severe pain; and 10, severe and constant pain. Overall pain was measured on a scale of $0-10$ because it provides a broad range for inclusion of daily activity. Pain after limb manipulation, on a scale of $0-4$, was graded as: 0 , no pain; 1 , mild pain; 2 , moderate pain; 3 , severe pain; and 4, severe and constant pain. Pain after physical exertion, on a scale of $0-4$, was graded as: 0 , no pain; 1 , mild pain; 2 , moderate pain; 3 , severe pain; and 4, severe and constant pain. Examination of each limb started with forelimbs and ended with rear limbs. The evaluation was focused on manipulation of the limbs in a forward, backward, and circular motion. The three main joints commonly evaluated were shoulder joint, knee joint, and stifle joint. Each dog was also evaluated for popping and cracking of the joint (crepitus) as well as vocalization due to pain. The present investigation was carried out on moderately arthritic dogs. A dog was considered moderately arthritic when exhibiting overall pain of about 5 on the scale of $0-10$; pain after limb manipulation about 2 on the scale of $0-4$; and pain after physical exertion about 2 on the scale of $0-4$. Details of pain measurement criteria by observations have been described in our previous publications $[13,16,30,62]$.

Radiographic evaluation: Arthritic joints (elbow and stifle) were evaluated radiographically using a DUOCON 1 VIDEX MACHLETT (125 KVP) equipped with digital imaging software on day 0 and day 150.

Liver, kidney, heart and skeletal muscle functions: On a monthly basis, blood samples were collected in serum separator tubes from jugular vein or cephalic vein. Serum samples were assayed for liver (bilirubin, ALT, and AST), kidney (BUN and creatinine) and heart and skeletal muscle (CK) functions, using a Beckman AU480 Chem Serum Analyzer (Irvining, TX, USA).

Blood analysis for complete blood count (CBC) and erythrocyte sedimentation rate (ESR): On a monthly basis, blood samples were collected in EDTA tubes from jugular vein or cephalic vein, and assayed for complete blood count (CBC) with white cell differential, using the Sysmex XT 2000iV system (Mundelein, IL, USA). Blood samples were also assayed for erythrocyte sedimentation rate (ESR) using a Sedi-RateTM ESR System to measure the level of inflammation.

Statistical analysis: Data were statistically analyzed for Mean \pm SEM and Analysis of Variance (ANOVA) coupled with Tukey-Kramer multiple comparison test for significance (Alpha $=0.05$ ) using NCSS9 software.

\section{Results}

Data presented in Table 1 show the results of body weight, heart rate and body temperature of dogs receiving placebo and T. chebula extract (TCE). At no time point did dogs in either group show a significant difference in body weight, heart rate, or body temperature, compared to day $0(\mathrm{P}>0.05)$. 
Citation: Murdock N, Gupta CR, Vega N, Kotora K, Miller J, et al. (2016) Evaluation of Terminalia chebula Extract for Anti-Arthritic Efficacy and Safety in Osteoarthritic Dogs . J Veterinar Sci Technol 7: 290. doi:10.4172/2157-7579.1000290

Page 3 of 8

\begin{tabular}{|l|l|l|l|l|l|l|l|}
\hline Parameter & $\begin{array}{l}\text { Control/ } \\
\text { Treated }\end{array}$ & Day 0 & Day 30 & Day 60 & Day 90 & Day 120 & Day 150 \\
\hline Body weight $(\mathrm{kg})$ & Control & $28.49 \pm 1.48$ & $28.59 \pm 1.60$ & $27.66 \pm 1.78$ & $28.76 \pm 1.35$ & $28.14 \pm 1.49$ & $28.39 \pm 1.31$ \\
\cline { 2 - 8 } & Treated & $24.20 \pm 2.05$ & $24.24 \pm 2.28$ & $24.86 \pm 1.95$ & $24.91 \pm 1.81$ & $23.99 \pm 2.28$ & $23.90 \pm 2.71$ \\
\hline Heart beat (Beats/ $\mathrm{min})$ & Control & $121.6 \pm 10.48$ & $114.8 \pm 5.20$ & $122.4 \pm 6.76$ & $131.6 \pm 6.58$ & $122.4 \pm 4.66$ & $122.4 \pm 6.88$ \\
\cline { 2 - 8 } & Treated & $131.2 \pm 11.27$ & $126.4 \pm 7.86$ & $128.8 \pm 7.94$ & $130.4 \pm 3.25$ & $125.0 \pm 5.51$ & $139.0 \pm 10.75$ \\
\hline Body temperature $\left({ }^{\circ} \mathrm{F}\right)$ & Control & $101.76 \pm 0.36$ & $101.10 \pm 0.18$ & $101.44 \pm 0.29$ & $101.14 \pm 0.16$ & $101.40 \pm 0.33$ & $101.14 \pm 0.15$ \\
\cline { 2 - 8 } & Treated & $101.12 \pm 0.45$ & $101.5 \pm 0.23$ & $100.92 \pm 0.20$ & $101.06 \pm 0.30$ & $101.68 \pm 0.23$ & $101.63 \pm 0.38$ \\
\hline
\end{tabular}

Table 1: Effects of placebo or T. chebula extract on physical parameters in arthritic dogs. No statistically significant difference from day 0 $(\mathrm{P}>0.05)$.

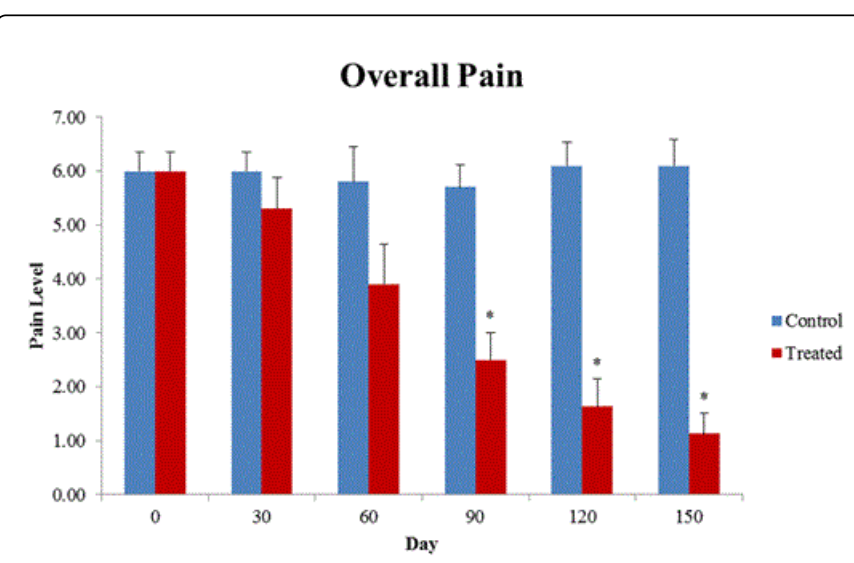

Figure 1: Effects of placebo or T. chebula Extract on overall pain in arthritic dogs. Values significantly different from day $0(\mathrm{P}<0.05)$.

Figure 1 shows the results of overall pain in dogs receiving placebo (Group I) or TCE (Group II). Dogs on placebo exhibited no significant change in pain level as compared to day $0(\mathrm{P}>0.05)$. Overall pain in dogs receiving TCE was significantly $(\mathrm{P}<0.05)$ reduced by day $90(2.50$ $\pm 0.50)$ as compared to day $0(6.00 \pm 0.35)$. The pain level was maximally reduced $(1.13 \pm 0.38)$ on day $150(81.2 \%)$.

Figure 2 presents the pain level after limb manipulation in dogs receiving placebo or TCE. Dogs on placebo exhibited no significant change in pain at any time compared with day $0(\mathrm{P}>0.05)$. TCE-treated dogs showed significant reduction in pain upon limb manipulation by day $90(1.10 \pm 0.33)$ compared to day $0(2.70 \pm 0.2)$. The maximum pain reduction $(0.5 \pm 0.20)$ was observed on day $150(81.5 \%)$.

Data in Figure 3 present pain after physical exertion in dogs receiving placebo or TCE for a period of 150 days. Dogs on placebo showed no significant reduction in pain at any time point compared to day 0 . TCE-treated dogs exhibited significant reduction in pain on day $90(1.20 \pm 0.34)$ compared to day $0(2.50 \pm 0.19)$. Maximal pain reduction $(0.38 \pm 0.13)$ was noted on day $150(84.2 \%)$.

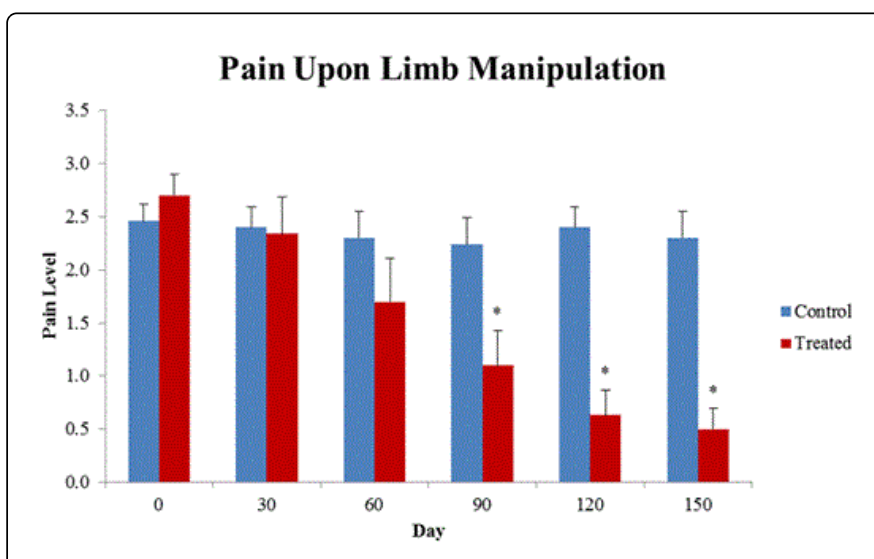

Figure 2: Effects of placebo or T. chebula Extract on pain upon limb manipulation in arthritic dogs. ${ }^{*}$ Values significantly different from day $0(\mathrm{P}<0.05)$.

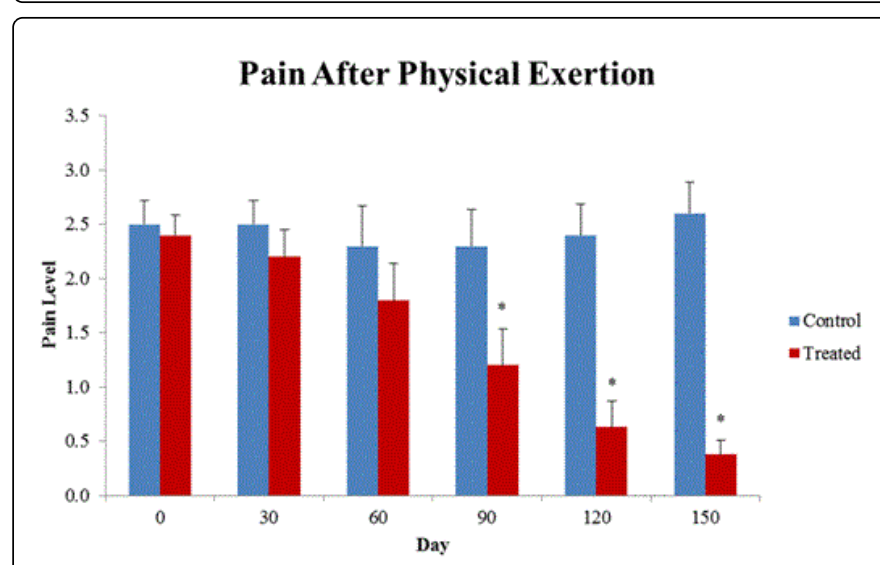

Figure 3: Effects of placebo or T. chebula extract on pain after physical exertion in arthritic dogs. Values significantly different from day $0(\mathrm{P}<0.05)$.

Data of erythrocyte sedimentation rate (ESR) in dogs receiving placebo or TCE are shown in Table 2. No significant reduction in ESR was noted at any time point in dogs on placebo. Dogs receiving TCE 
Citation: Murdock N, Gupta CR, Vega N, Kotora K, Miller J, et al. (2016) Evaluation of Terminalia chebula Extract for Anti-Arthritic Efficacy and Safety in Osteoarthritic Dogs . J Veterinar Sci Technol 7: 290. doi:10.4172/2157-7579.1000290

Page 4 of 8

showed significant $(\mathrm{P}<0.05)$ reduction in ESR on day $120(0.63 \pm 0.47)$ with a maximum reduction on day $150(0.38 \pm 0.38)$ compared to day $0(2.40 \pm 0.68)$, suggesting a marked reduction in inflammation.

Left stifle of a dog on placebo show exostosis involving the distal femur, proximal tibia, and patella (Figure 4). The radiographic changes noted are more severe in the radiograph taken on Day 150 , which validates the normal progression of $\mathrm{OA}$ in the placebo group. Radiographically, the left stifle demonstrates how the body is attempting to stabilize an unstable joint by the process of bone formation. This is the normal disease progression of OA clinically as an animal attempts to make use of the joint.

\begin{tabular}{|l|l|l|l|l|l|l|l|}
\hline Parameter & Control/Treated & Day 0 & Day 30 & Day $\mathbf{6 0}$ & Day 90 & Day 120 & Day 150 \\
\hline ESR & Control & $4.00 \pm 2.01$ & $3.80 \pm 2.60$ & $4.30 \pm 2.43$ & $4.30 \pm 2.68$ & $7.20 \pm 5.70$ & $5.20 \pm 3.45$ \\
\cline { 2 - 7 } & Treated & $2.40 \pm 0.68$ & $2.00 \pm 0.32$ & $1.20 \pm 0.37$ & $1.30 \pm 0.77$ & $0.63 \pm 0.47^{*}$ & $0.38 \pm 0.38^{*}$ \\
\hline
\end{tabular}

Table 2: Effects of placebo or T. chebula extract on erythrocyte sedimentation rate (ESR) in arthritic dogs. ${ }^{*}$ Values significantly different from day $0(\mathrm{P}<0.05)$.

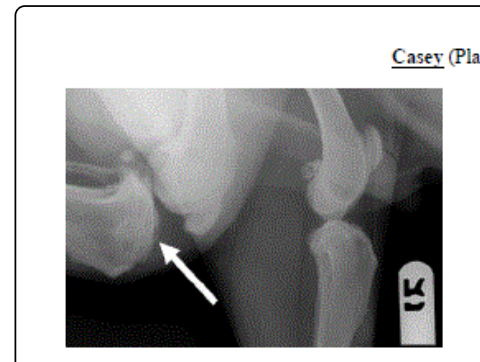

Day 0

Figure 4: Radiographs of the left stifle of a dog on placebo has exostosis involving the distal femur, proximal tibia, and patella.

Radiographs obtained of the right humero-radial (elbow) joint from a dog receiving TCE showed a slowed progression of bone formation in a typical arthritic joint (Figure 5). The amount of exostosis involving the distal humerus, radius, and ulna is not what one would expect to observe in a 150 day interval. Minor radiographic sclerosis of the articular surfaces is observed. The comparison of the Day 1 versus Day 150 radiographs show some arthritic progression, but at a much slower pace than is typical in an OA joint.

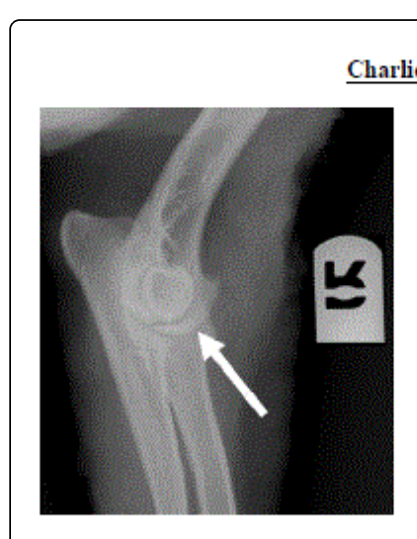

Day 0 harlie (Treatment)

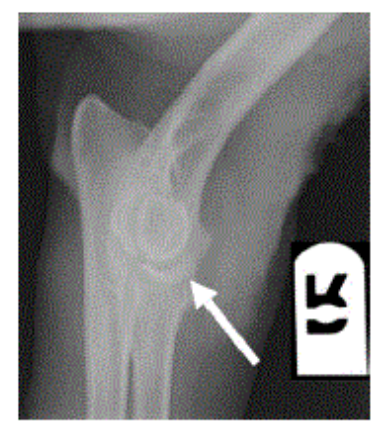

Daỵ 150
Figure 5: Radiographs obtained of the right humero-radial (elbow) joint from a dog receiving TCE showed a slowed progression of bone formation in a typical arthritic joint.

Serum chemistry and CBC data of dogs treated with placebo or TCE are presented in Tables 3 and 4, respectively. Neither placebo nor TCE treated dogs showed a statistically significant difference from Day 0 for any serum chemistry or $\mathrm{CBC}$ parameters $(\mathrm{P}>0.5)$. One participant had consistently increased levels in RBC, HGB, and HCT. This was likely due to a difficult blood collection.

\begin{tabular}{|c|c|c|c|c|c|c|c|}
\hline Parameter & $\begin{array}{l}\text { Control/ } \\
\text { Treated }\end{array}$ & Day 0 & Day 30 & Day 60 & Day 90 & Day 120 & Day 150 \\
\hline \multirow[t]{2}{*}{ Total Bilirubin (mg/dl) } & Control & $0.22 \pm 0.02$ & $0.18 \pm 0.05$ & $0.16 \pm 0.02$ & $0.14 \pm 0.02$ & $0.18 \pm 0.02$ & $0.18 \pm 0.02$ \\
\hline & Treated & $0.16 \pm 0.02$ & $0.20 \pm 0.04$ & $0.18 \pm 0.04$ & $0.26 \pm 0.04$ & $0.20 \pm 0.00$ & $0.20 \pm 0.04$ \\
\hline \multirow[t]{2}{*}{ ALT/(IU/L) } & Control & $84.20 \pm 29.19$ & $87.20 \pm 33.38$ & $88.60 \pm 29.86$ & $80.20 \pm 23.81$ & $71.60 \pm 20.14$ & $76.40 \pm 26.12$ \\
\hline & Treated & $59.20 \pm 10.37$ & $42.80 \pm 8.89$ & $50.00 \pm 9.41$ & $223.80 \pm 173.90$ & $45.25 \pm 8.82$ & $35.75 \pm 6.02$ \\
\hline \multirow[t]{2}{*}{ AST(IU/L) } & Control & $27.80 \pm 2.78$ & $25.20 \pm 2.48$ & $22.00 \pm 1.64$ & $25.80 \pm 1.88$ & $31.00 \pm 6.41$ & $24.00 \pm 2.85$ \\
\hline & Treated & $26.40 \pm 2.42$ & $26.60 \pm 1.03$ & $28.40 \pm 1.60$ & $56.20 \pm 31.28$ & $23.25 \pm 1.75$ & $25.75 \pm 2.39$ \\
\hline $\mathrm{BUN}(\mathrm{mg} / \mathrm{dL})$ & Control & $18.80 \pm 2.94$ & $20.00 \pm 3.15$ & $17.60 \pm 1.08$ & $18.80 \pm 1.88$ & $17.00 \pm 0.89$ & $20.60 \pm 2.27$ \\
\hline
\end{tabular}


Citation: Murdock N, Gupta CR, Vega N, Kotora K, Miller J, et al. (2016) Evaluation of Terminalia chebula Extract for Anti-Arthritic Efficacy and Safety in Osteoarthritic Dogs . J Veterinar Sci Technol 7: 290. doi:10.4172/2157-7579.1000290

Page 5 of 8

\begin{tabular}{|l|l|l|l|l|l|l|l|}
\hline & Treated & $13.40 \pm 1.83$ & $12.20 \pm 1.43$ & $14.00 \pm 1.05$ & $15.40 \pm 3.20$ & $14.75 \pm 2.81$ & $13.00 \pm 2.94$ \\
\hline Creatinine $(\mathrm{mg} / \mathrm{dL})$ & Control & $0.93 \pm 0.08$ & $1.00 \pm 0.07$ & $0.99 \pm 0.07$ & $1.00 \pm 0.08$ & $1.00 \pm 0.08$ & $1.00 \pm 0.06$ \\
\cline { 2 - 8 } & Treated & $0.89 \pm 0.09$ & $0.85 \pm 0.07$ & $0.88 \pm 0.07$ & $0.85 \pm 0.10$ & $0.86 \pm 0.05$ & $0.88 \pm 0.08$ \\
\hline CK (IU/L) & Control & $116.20 \pm 21.77$ & $96.60 \pm 12.23$ & $88.20 \pm 11.40$ & $138.00 \pm 39.54$ & $325.80 \pm 171.67$ & $135.60 \pm 39.17$ \\
\cline { 2 - 8 } & Treated & $133.00 \pm 28.09$ & $3.80 \pm 2.60$ & $4.30 \pm 2.43$ & $4.30 \pm 2.68$ & $7.20 \pm 5.70$ & $5.20 \pm 3.45$ \\
\hline
\end{tabular}

Table 3: Effects of placebo or T. chebula extract on serum chemistry parameters in arthritic dogs. No statistically significant difference from day 0 $(\mathrm{P}>0.05)$.

\begin{tabular}{|c|c|c|c|c|c|c|c|}
\hline Parameter & $\begin{array}{l}\text { Control/ } \\
\text { Treated }\end{array}$ & Day 0 & Day 30 & Day 60 & Day 90 & Day 120 & Day 150 \\
\hline \multirow[t]{2}{*}{$\mathrm{RBC}(106 / \mu \mathrm{L})$} & Control & $6.77 \pm 0.32$ & $7.03 \pm 0.24$ & $6.84 \pm 0.16$ & $6.78 \pm 0.16$ & $6.93 \pm 0.28$ & $6.75 \pm 0.09$ \\
\hline & Treated & $8.19 \pm 0.02$ & $7.89 \pm 0.41$ & $7.96 \pm 0.44$ & $8.04 \pm 0.30$ & $8.37 \pm 0.27$ & $7.91 \pm 0.19$ \\
\hline \multirow[t]{2}{*}{ WBC $(103 / \mu \mathrm{L})$} & Control & $7.61 \pm 0.80$ & $8.11 \pm 0.73$ & $7.97 \pm 0.84$ & $8.47 \pm 0.79$ & $8.54 \pm 0.78$ & $9.37 \pm 0.81$ \\
\hline & Treated & $8.55 \pm 1.29$ & $8.77 \pm 1.50$ & $8.87 \pm 1.21$ & $9.03 \pm 1.02$ & $9.89 \pm 0.76$ & $9.68 \pm 1.48$ \\
\hline \multirow[t]{2}{*}{$\mathrm{HGB}(\mathrm{g} / \mathrm{dL})$} & Control & $16.74 \pm 0.55$ & $16.86 \pm 0.74$ & $16.50 \pm 0.66$ & $16.58 \pm 0.74$ & $16.78 \pm 0.96$ & $16.64 \pm 0.60$ \\
\hline & Treated & $19.04 \pm 0.47$ & $18.46 \pm 0.88$ & $16.50 \pm 0.66$ & $16.58 \pm 0.74$ & $16.78 \pm 0.96$ & $16.64 \pm 0.60$ \\
\hline \multirow[t]{2}{*}{ HCT (\%) } & Control & $52.26 \pm 0.61$ & $50.46 \pm 1.67$ & $18.78 \pm 1.02$ & $19.54 \pm 0.77$ & $19.75 \pm 0.58$ & $18.65 \pm 0.30$ \\
\hline & Treated & $58.22 \pm 2.49$ & $54.30 \pm 2.56$ & $55.60 \pm 2.74$ & $54.74 \pm 1.77$ & $56.53 \pm 1.94$ & $54.73 \pm 1.75$ \\
\hline \multirow[t]{2}{*}{ MCV (fL) } & Control & $74.14 \pm 1.82$ & $71.80 \pm 1.46$ & $71.94 \pm 1.14$ & $70.30 \pm 1.13$ & $72.86 \pm 0.88$ & $72.56 \pm 1.77$ \\
\hline & Treated & $71.08 \pm 2.32$ & $68.94 \pm 0.89$ & $69.52 \pm 1.13$ & $68.24 \pm 1.48$ & $67.55 \pm 1.39$ & $69.23 \pm 1.76$ \\
\hline \multirow[t]{2}{*}{$\mathrm{MCH}(\mathrm{pg})$} & Control & $23.68 \pm 0.42$ & $23.94 \pm 0.50$ & $24.12 \pm 0.59$ & $24.40 \pm 0.57$ & $24.14 \pm 0.52$ & $24.62 \pm 0.58$ \\
\hline & Treated & $23.26 \pm 0.35$ & $23.42 \pm 0.32$ & $23.60 \pm 0.30$ & $24.32 \pm 0.62$ & $23.65 \pm 0.41$ & $23.60 \pm 0.40$ \\
\hline \multirow[t]{2}{*}{$\mathrm{MCHC}(\mathrm{g} / \mathrm{dL})$} & Control & $32.02 \pm 0.91$ & $33.36 \pm 0.49$ & $33.50 \pm 0.44$ & $34.76 \pm 0.67$ & $33.10 \pm 0.38$ & $34.00 \pm 0.96$ \\
\hline & Treated & $32.82 \pm 0.93$ & $34.02 \pm 0.07$ & $33.98 \pm 0.32$ & $35.68 \pm 0.50$ & $34.98 \pm 0.33$ & $34.15 \pm 0.63$ \\
\hline
\end{tabular}

Table 4: Effects of placebo or T. chebula extract on cbc parameters in arthritic dogs. No statistically significant difference from day 0 ( $\mathrm{P}>0.05)$.

\section{Discussion}

The present investigation was carried out with a hypothesis that daily oral administration of Terminalia chebula extract (TCE, $1000 \mathrm{mg}$ in two divided doses) in moderately OA dogs will ameliorate the signs of OA and TCE will be well tolerated. Some of the highlighted findings of the present investigation are mentioned here in brief. It was noteworthy from Figures 1-3 that TCE significantly $(\mathrm{P}<0.05)$ reduced OA associated pain (81-84\%) in dogs, using different criteria (overall pain, pain upon limb manipulation, and pain after physical exertion). TCE-treated dogs had markedly reduced erythrocyte sedimentation rate (ESR), a biomarker of inflammation, suggesting a decline in inflammation (Table 2). Interestingly, timing of reduction in ESR/ inflammation coincided with a decline in arthritic pain. The levels of arthritic pain and ESR remained the same or slightly elevated in dogs receiving placebo. Radiographic evidence suggested that dogs treated with TCE for 150 days exhibited a very slow pace of arthritic progression compared to those receiving placebo (Figures 4 and 6, respectively). Dogs receiving placebo or TCE did not experience any untoward effects, and no significant change occurred in serum markers or $\mathrm{CBC}$ during the period of this investigation, which suggested that TCE was well tolerated.

Dogs with OA may show clinical signs of limping, stiffness of joints, immobility, crepitus, periarticular swelling, and lameness. Pain associated with inflammation appears to be the most serious sign of OA $[3,11-16,30]$. As stated in the introduction, pathophysiology of OA is very complex due to involvement of multiple factors $[18,20-26]$. Among all these factors, oxidative stress (due to excess generation of free radicals) and inflammation are proven to be the major contributing factors in joint damage and pain [67-71].

TCE consists of many biologically active principles (chebulagic acid, chebulinic acid, chebulic acid, gallic acid, ellagic acid, tannic acid, corilagin, polyphenolic compounds, triterpenoids, and ascorbate). Chebulagic acid and chebulinic acid are the major constituents and their chemical structures are shown in Figure 6. In experimental and human studies, TCE and its components have been shown to exert antioxidant, anti-inflammatory and analgesic activities, thereby exerting anti-arthritic effects [72-82]. Das et al. [83] demonstrated that 
gallic acid in TCE inhibited NF- $\kappa \mathrm{B}$ activity, suggesting its potential for anti-inflammatory activity. In another study, Reddy et al. [84] have shown that chebulagic acid exerts anti-inflammatory and antiproliferative actions by inhibiting activities of COX2 and 5lipoxygenase (5-LOX), the key enzymes involved in inflammation. In a recent study, Martinez et al. (2015) reported that a C-phycocyaninbased nutraceutical may provide anti-inflammatory activity by inhibiting COX (preferentially COX-2) and LOX activities. Findings of these investigations corroborated with observations of the present study, supporting TCE-induced antioxidant, anti-inflammatory and anti-arthritic properties in OA dogs. It is highly probable that the observed anti-inflammatory effect was exerted by the active principles (chebulagic acid, gallic acid, polyphenols and other bio-active compounds) present in TCE.
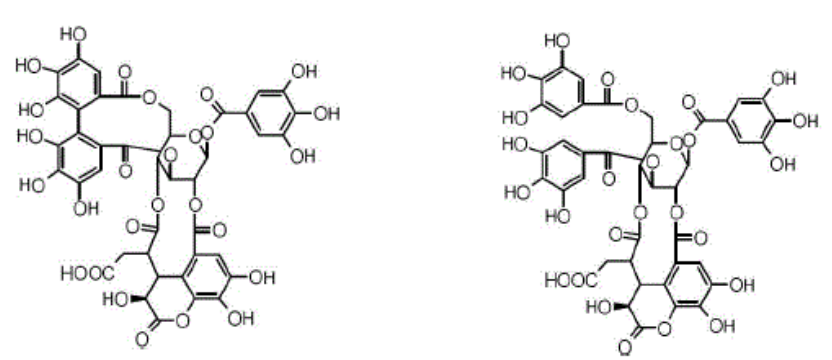

Chebulagic Acid

Chebulinic Acid

Figure 6: Chemical structures of chebulagic acid and chebulinic acid.

Additional properties of TCE, such as nutritional, physiological [85], adaptogenic, immunomodulatory [86-88], and other pharmacological actions $[66,78,79,83,89-93]$ might have played roles in the treatment of arthritic dogs. In our recent investigations, nutraceuticals such as purified Shilajit and Crominex $3+$, by having antioxidant and anti-inflammatory properties, also significantly ameliorated pain and other signs of OA in dogs $[16,30]$.

In conclusion, significant reductions in pain and inflammation, and improvement in joint cartilage and daily activity in dogs treated with TCE might be due to the effects of several pharmacologically active compounds exerting multiple mechanisms, including anti-oxidant and free radical scavenging, anti-inflammatory, anti-proliferative, immunomodulatory, and cytoprotective activities. TCE has a great potential for treatment of OA and has been found to be safe for longterm use. Detailed mechanistic studies need to be explored, and longterm large scale clinical trials in OA prone species (canine, equine, and humans) need to be pursued.

\section{Acknowledgement}

This investigation was supported in part by Natreon, Inc (New Brunswick, NJ, USA).

\section{References}

1. Paster ER, LaFond E, Biery DN, Iriye A, Gregor TP, et al. (2005) Estimates of prevalence of hip dysplasia in Golden Retrievers and Rottweilers and the influence of bias on published prevalence figures. J Am Vet Med Assoc 226: 387-392.
2. Smith GK, Paster ER, Powers MY, Lawler DF, Biery DN, et al. (2006) Lifelong diet restriction and radiographic evidence of osteoarthritis of the hip joint in dogs. J Am Vet Med Assoc 229: 690-693.

3. Rialland P, Bichot S, Moreau M, Guillot M, Lussier B, et al. (2012) Clinical validity of outcome pain measures in naturally occurring canine osteoarthritis. BMC Vet Res 8: 162.

4. Martinez SA, Coronado GS (1997) Acquired conditions that lead to osteoarthritis in the dog. Vet Clin North Am Small Anim Pract 27: 759-775.

5. Valdes AM, Spector TD (2008) The contribution of genes to osteoarthritis. Rheum Dis Clin North Am 34: 581-603.

6. Perea S (2012) Nutritional management of osteoarthritis. Compend Contin Educ Vet 34: E4.

7. Loeser RF (2013) Aging processes and the development of osteoarthritis. Curr Opin Rheumatol 25: 108-113.

8. Arthritis Foundation (2013) Spotting arthritis in spot.

9. Elliot D (2007) Nutritional management of canine arthritis. Veterinary Focus 17: 43-48

10. ASPCA (2013) Hip Dysplasia.

11. Hielm-Björkman AK, Kuusela E, Liman A, Markkola A, Saarto E, et al. (2003) Evaluation of methods for assessment of pain associated with chronic osteoarthritis in dogs. J Am Vet Med Assoc 222: 1552-1558.

12. Renberg WC (2005) Pathophysiology and management of arthritis. Vet Clin North Am Small Anim Pract 35: 1073-1091.

13. Gupta RC, Canerdy TD, Lindley J, et al. (2012) Comparative therapeutic efficacy and safety of type-II collagen (UC-II), glucosamine and chondroitin in arthritic dogs: pain evaluation by ground force plate. J Anim Physiol Anim Nutri 96: 770-777.

14. Osteoarthritis in Dogs (2012) Osteoarthritis in Dogs-Signs and Symptoms of Arthritis and Osteoarthritis.

15. Fahie MA, Ortolano GA, Guercio V, Schaffer JA, Johnston G, et al. (2013) A randomized controlled trial of the efficacy of autologous platelet therapy for the treatment of osteoarthritis in dogs. J Am Vet Med Assoc 243: 1291-1297.

16. Fleck A, Gupta RC, Goad JT, Lasher MA, Canerdy TD, et al. (2013) Antiarthritic efficacy and safety of Crominex ${ }^{\circ} 3+$ (trivalent chromium, Phyllanthus emblica extract, and Shilajit) in moderately arthritic dogs. J Vet Sci Anim Husb 1: 1-8.

17. Dieppe PA, Lohmander LS (2005) Pathogenesis and management of pain in osteoarthritis. Lancet 365: 965-973.

18. Brandt KD, Dieppe P, Radin EL (2009) Etiopathogenesis of osteoarthritis. Rheum Dis Clin North Am 34: 531-559.

19. Leong DJ, Choudhury M, Hirsh DM, Hardin JA, Cobelli NJ, et al. (2013) Nutraceuticals: potential for chondroprotection and molecular targeting of osteoarthritis. Int J Mol Sci 14: 23063-23085.

20. Gupta RC (2015) Nutraceuticals in arthritis. In Nutraceuticals: Efficacy, Safety and Toxicity.

21. Muir HCS (1987) Pathological and biochemical changes in cartilage and other tissues of the canine knee resulting from induced joint instability. In: Joint Loading: Biology and Health of Articular Structures. Bristol, pp. 47-63.

22. Vaughan-Scott T, Taylor JH (1997) The pathophysiology and medical management of canine osteoarthritis. J S Afr Vet Assoc 68: 21-25.

23. Krasnokutsky S, Attur M, Palmer G, Samuels J, Abramson SB (2008) Current concepts in the pathogenesis of osteoarthritis. Osteoarthritis Cartilage 16: S1-3.

24. Abramson SB, Attur M (2009) Developments in the scientific understanding of osteoarthritis. Arthritis Res Ther 11: 227.

25. Sharma AR, Jagga S, Lee SS, Nam JS (2013) Interplay between cartilage and subchondral bone contributing to pathogenesis of osteoarthritis. Int $J$ Mol Sci 14: 19805-19830.

26. Tonge DP, Pearson MJ, Jones SW (2014) The hallmarks of osteoarthritis and the potential to develop personalized disease-modifying pharmacological therapeutics. Osteoarthr Cartil 22: 609-621. 
27. Gupta RC (Editor) Academic Press/Elsevier, Amsterdam, pp. 161-176.

28. Martinez SE, Chen Y, Ho EA, Martinez SA, Davies NM (2015) Pharmacological effects of a C-phycocyanin-based multicomponent nutraceutical in an in vitro canine chondrocyte model of osteoarthritis. Can J Vet Res 79: 241-249.

29. Rychel JK (2010) Diagnosis and treatment of osteoarthritis. Top Companion Anim Med 25: 20-25.

30. Lawley S, Gupta RC, Goad JT, Canerdy TD, Kalidindi SR (2013) Antiinflammatory and anti-arthritic efficacy and safety of purified Shilajit in moderately arthritic dogs. J Vet Sci Anim Husb 1: 1-6.

31. Piscaer TM, Waarsing JH, Kops N, Pavljasevic P, Verhaar JA, et al. (2008) In vivo imaging of cartilage degeneration using microCT-arthrography. Osteoarthritis Cartilage 16: 1011-1017.

32. Kumar D, Wyatt CR, Lee S, Nardo L, Link TM, et al. (2013) Association of cartilage defects, and other MRI findings with pain and function in individuals with mild-moderate radiographic hip osteoarthritis and controls. Osteoarthritis Cartilage 21: 1685-1692.

33. Eckstein F, Guermazi A, Gold G, Duryea J, Hellio Le Graverand MP, et al. (2014) Imaging of cartilage and bone: promises and pitfalls in clinical trials of osteoarthritis. Osteoarthritis Cartilage 22: 1516-1532.

34. Roudebush P (2006) Pain management for canine osteoarthritis. Proc North Am Vet Conf 20: 1007-1010.

35. Rialland P, Bichot S, Lussier B, Moreau M, Beaudry F, et al. (2013) Effect of a diet enriched with green-lipped mussel on pain behavior and functioning in dogs with clinical osteoarthritis. Can J Vet Res 77: 66-74.

36. Pelletier JP, Caron JP, Evans C, Robbins PD, Georgescu HI, et al. (1997) In vivo suppression of early experimental osteoarthritis by interleukin-1 receptor antagonist using gene therapy. Arthritis Rheum 40: 1012-1019.

37. Fajardo M, Di Cesare PE (2005) Disease-modifying therapies for osteoarthritis : current status. Drugs Aging 22: 141-161.

38. Schoenherr WD (2005) Comprehensive nutritional management of canine osteoarthritis. Proc North Am Vet Conf 19: 783-784.

39. Sawaya $S$ (2007) Physical and alternative therapies in the management of arthritic patients. IVIS Vet Focus 17: 37-42.

40. Sanderson RO, Beata C, Flipo RM, Genevois JP, Macias C, et al. (2009) Systematic review of the management of canine osteoarthritis. Vet Rec 164: 418-424.

41. Vilar JM, Batista M, Morales M, Santana A, Cuervo B, et al. (2014) Assessment of the effect of intraarticular injection of autologous adiposederived mesenchymal stem cells in osteoarthritic dogs using a double blinded force platform analysis. BMC Vet Res 10: 143.

42. Moreau M, Dupuis J, Bonneau NH, Desnoyers M (2003) Clinical evaluation of a nutraceutical, carprofen and meloxicam for the treatment of dogs with osteoarthritis. Vet Rec 152: 323-329.

43. Lascelles BD, McFarland JM, Swann H (2005) Guidelines for safe and effective use of NSAIDs in dogs. Vet Ther 6: 237-251.

44. Dwivedi AK, Gurjar V, Kumar S, Singh N (2015) Molecular basis for nonspecificity of nonsteroidal anti-inflammatory drugs (NSAIDs). Drug Discov Today 20: 863-873

45. Bergh MS, Budsberg SC (2005) The coxib NSAIDs: potential clinical and pharmacologic importance in veterinary medicine. J Vet Intern Med 19: 633-643.

46. Innes JF, Clayton J, Lascelles BD (2010) Review of the safety and efficacy of long-term NSAID use in the treatment of canine osteoarthritis. Vet Rec 166: 226-230.

47. Wolf G, Porth J, Stahl RA (2000) Acute renal failure associated with rofecoxib. Ann Intern Med 133: 394.

48. Hörl WH (2010) Nonsteroidal anti-inflammatory drugs and the kidney. Pharmaceuticals 3: 2291-2321.

49. Cheng HH, Chou CT, Sun TK, Liang WZ, Cheng JS, et al. (2015) Naproxen-induced $\mathrm{Ca} 2+$ movement and death in MDCK canine renal tubular cells. Hum Exp Toxicol 34: 1096-1105.

50. Lobetti RG, Joubert KE (2000) Effect of administration of nonsteroidal anti-inflammatory drugs before surgery on renal function in clinically normal dogs. Am J Vet Res 61: 1501-1507.
51. Sessions JK1, Reynolds LR, Budsberg SC (2005) In vivo effects of carprofen, deracoxib, and etodolac on prostanoid production in blood, gastric mucosa, and synovial fluid in dogs with chronic osteoarthritis. Am J Vet Res 66: 812-817.

52. Raekallio MR, Hielm-Björkman AK, Kejonen J, Salonen HM, Sankari SM (2006) Evaluation of adverse effects of long-term orally administered carprofen in dogs. J Am Vet Med Assoc 228: 876-880.

53. Coruzzi G, Venturi N, Spaggiari S (2007) Gastrointestinal safety of novel nonsteroidal antiinflammatory drugs: selective COX-2 inhibitors and beyond. Acta Biomed 78: 96-110.

54. Monteiro-Steagall BP, Steagall PV, Lascelles BD (2013) Systematic review of nonsteroidal anti-inflammatory drug-induced adverse effects in dogs. J Vet Intern Med 27: 1011-1019.

55. Barry S (2010) Non-steroidal anti-inflammatory drugs inhibit bone healing: a review. Vet Comp Orthop Traumatol 23: 385-392.

56. Lees P, Pelligand L, Elliott J, Toutain PL, Michels G, et al. (2015) Pharmacokinetics, pharmacodynamics, toxicology and therapeutics of mavacoxib in the dog: a review. J Vet Pharmacol Ther 38: 1-14.

57. Vandeweerd JM, Coisnon C, Clegg P, Cambier C, Pierson A, et al. (2012) Systematic review of efficacy of nutraceuticals to alleviate clinical signs of osteoarthritis. J Vet Intern Med 26: 448-456.

58. Comblain F, Serisier S, Barthelemy N, Balligand M, Henrotin Y, et al. (2015) Review of dietary supplements for the management of osteoarthritis in dogs in studies from 2004 to 2014. J Vet Pharmacol Ther .

59. Henrotin Y, Sanchez C, Balligand M (2005) Pharmaceutical and nutraceutical management of canine osteoarthritis: present and future perspectives. Vet J 170: 113-123.

60. Neil KM, Caron JP, Orth MW (2005) The role of glucosamine and chondroitin sulfate in treatment for and prevention of osteoarthritis in animals. J Am Vet Med Assoc 226: 1079-1088.

61. McCarthy G, O'Donovan J, Jones B, McAllister H, Seed M, et al. (2007) Randomised double-blind, positive-controlled trial to assess the efficacy of glucosamine/chondroitin sulfate for the treatment of dogs with osteoarthritis. Vet J 174: 54-61.

62. D'Altilio M, Peal A, Alvey M, Simms C, Curtsinger A, et al. (2007) Therapeutic Efficacy and Safety of Undenatured Type II Collagen Singly or in Combination with Glucosamine and Chondroitin in Arthritic Dogs. Toxicol Mech Methods 17: 189-196.

63. Boileau C, Martel-Pelletier J, Caron J, et al. (2009) Protective effects of total fraction of avocado/soybean unsaponifiables on the structural changes in experimental dog osteoarthritis: inhibition of nitric oxide synthase and matrix metalloproteinase-13. Arthr Res Therap 11: R41.

64. Hielm-Björkman A, Tulamo RM, Salonen H, Raekallio M (2009) Evaluating Complementary Therapies for Canine Osteoarthritis Part I: Green-lipped Mussel (Perna canaliculus). Evid Based Complement Alternat Med 6: 365-373.

65. Colitti M, Gaspardo B, Della Pria A, Scaini C, Stefanon B (2012) Transcriptome modification of white blood cells after dietary administration of curcumin and non-steroidal anti-inflammatory drug in osteoarthritic affected dogs. Vet Immunol Immunopathol 147: 136-146.

66. Upadhyay A, Agrahari P, Singh DK (2014) A review on the pharmacological aspects of Terminalia chebula. Int J Pharmacol 10: 289-298.

67. Courties A, Gualillo O2, Berenbaum F3, Sellam J1 (2015) Metabolic stress-induced joint inflammation and osteoarthritis. Osteoarthritis Cartilage 23: 1955-1965.

68. Deligne C, Casulli S, Pigenet A, Bougault C, Campillo-Gimenez L, et al. (2015) Differential expression of interleukin-17 and interleukin-22 in inflamed and non-inflamed synovium from osteoarthritis patients. Osteoarthritis Cartilage 23: 1843-1852.

69. Greene MA, Loeser RF (2015) Aging-related inflammation in osteoarthritis. Osteoarthritis Cartilage 23: 1966-1971.

70. Liu-Bryan R (2015) Inflammation and intracellular metabolism: new targets in OA. Osteoarthritis Cartilage 23: 1835-1842. 
Citation: Murdock N, Gupta CR, Vega N, Kotora K, Miller J, et al. (2016) Evaluation of Terminalia chebula Extract for Anti-Arthritic Efficacy and Safety in Osteoarthritic Dogs . J Veterinar Sci Technol 7: 290. doi:10.4172/2157-7579.1000290

Page 8 of 8

71. Rogers EL, Reynard LN, Loughlin J (2015) The role of inflammationrelated genes in osteoarthritis. Osteoarthritis Cartilage 23: 1933-1938.

72. Cheng HY, Lin TC, Yu KH, Yang CM, Lin CC (2003) Antioxidant and free radical scavenging activities of Terminalia chebula. Biol Pharm Bull 26: 1331-1335.

73. Na M, Bae K, Kang SS, Min BS, Yoo JK, et al. (2004) Cytoprotective effect on oxidative stress and inhibitory effect on cellular aging of Terminalia chebula fruit. Phytother Res 18: 737-741.

74. Lee HS, Won NH, Kim KH, Lee H, Jun W, et al. (2005) Antioxidant effects of aqueous extract of Terminalia chebula in vivo and in vitro. Biol Pharm Bull 28: 1639-1644.

75. Hazra B, Sarkar R, Biswas S, Mandal N (2010) Comparative study of the antioxidant and reactive oxygen species scavenging properties in the extracts of the fruits of Terminalia chebula, Terminalia belerica and Emblica officinalis. BMC Complement Altern Med 10: 20.

76. Nair V, Singh S, Gupta YK (2010) Anti-arthritic and disease modifying activity of Terminalia chebula Retz. in experimental models. J Pharm Pharmacol 62: 1801-1806.

77. Pfundstein B, El Desouky SK, Hull WE, Haubner R, Erben G, et al. (2010) Polyphenolic compounds in the fruits of Egyptian medicinal plants (Terminalia bellerica, Terminalia chebula and Terminalia horrida): characterization, quantitation and determination of antioxidant capacities. Phytochemistry 71: 1132-1148.

78. Chang CL, Lin CS (2012) Phytochemical composition, antioxidant activity, and neuroprotective effect of Terminalia chebula Retzius extracts. Evidence-Based Complment Alternat Med.

79. Joonmoni L, Babul KB, Upama S (2012) Analgesic and antipyretic activities of Terminalia chebula Retz fruits extracts in experimental animals. Int Res J Pharmaceut Appl Sci 2: 159-163.

80. Seo JB, Jeong JY, Park JY, Jun EM, Lee SI, et al. (2012) Anti-Arthritic and Analgesic Effect of NDI10218, a Standardized Extract of Terminalia chebula, on Arthritis and Pain Model. Biomol Ther (Seoul) 20: 104-112.

81. Gaire BP, Jamarkattel-Pandit N, Lee D, Song J, Kim JY, et al. (2013) Terminalia chebula extract protects OGD-R induced PC12 cell death and inhibits lps induced microglia activation. Molecules 18: 3529-3542.

82. Jami MS, Sultana Z, Ali ME, et al. (2014) Evaluation of analgesic and antiinflammatory activities on ethanolic extract of Terminalia chebula fruits in experimental animals. Am J Plant Sci 5: 63-69.
83. Das ND, Jung KH, Park JH, Mondol MA, Shin HJ, et al. (2011) Terminalia chebula extract acts as a potential NF- $\mathrm{kB}$ inhibitor in human lymphoblastic T cells. Phytother Res 25: 927-934.

84. Reddy DB, Reddy TC, Jyotsna G, Sharan S, Priya N, et al. (2009) Chebulagic acid, a COX-LOX dual inhibitor isolated from the fruits of Terminalia chebula Retz., induces apoptosis in COLO-205 cell line. J Ethnopharmacol 124: 506-512.

85. Barthakur NN, Arnold NP (1991) Nutritive value of the chebulinic myrobalan (Terminalia chebula Retz.) and its potential as a food source. Food Chem 40: 213-219.

86. Hamada S, Kataoka T, Woo JT, Yamada A, Yoshida T, et al. (1997) Immunosuppressive effects of gallic acid and chebulagic acid on CTLmediated cytotoxicity. Biol Pharm Bull 20: 1017-1019.

87. Shivaprasad HN, Kharya MD, Rana AC, Mohan S (2006) Preliminary immunomodulatory activities of the aqueous extract of Terminalia chebula. Pharmaceut Biol 44: 32-34.

88. Aher V, Wahi AK (2011) Immunomodulatory activity of alcohol extract of Terminalia chebula Retz Combretaceae. Trop J Pharmaceut Res 10: 567-575.

89. Reddy VRC, Kumari SVR, Reddy BM, et al. (1990) Cardiotonic activity of the fruit of Terminalia chebula. Fitoterapia LXI: 517-525.

90. Rao NK, Nammi S (2006) Antidiabetic and renoprotective effects of the chloroform extract of Terminalia chebula Retz. seeds in streptozotocininduced diabetic rats. BMC Complement Altern Med 6: 17.

91. Gopi KS, Reddy AG, Jyothi K, Kumar BA (2010) Acetaminopheninduced Hepato- and Nephrotoxicity and Amelioration by Silymarin and Terminalia chebula in Rats. Toxicol Int 17: 64-66.

92. Kaur S, Jaggi RK (2010) Antinociceptive activity of chronic administration of different extracts of Terminalia bellerica Roxb. and Terminalia chebula Retz. fruits. Indian J Exp Biol 48: 925-930.

93. Larun L, Brurberg KG, Odgaard-Jensen J, Price JR (2015) Exercise therapy for chronic fatigue syndrome. Cochrane Database Syst Rev 2: CD003200. 